\title{
Genetic interchange of Dreissena polymorpha populations across a canal
}

\author{
JAKOB MÜLLER*, SABRINA WÖLL, UTA FUCHS \& ALFRED SEITZ \\ Department of Population Biology, Zoological Institute, University of Mainz, 55099 Mainz, Germany
}

\begin{abstract}
The zebra mussel Dreissena polymorpha, has been invading western Central Europe since the early 19th century, coming from the Pontocaspian by two routes, each interconnected by large rivers and canals constructed at that time. By 1992 these two invasion populations had been given the opportunity to mix extensively across the newly built Main-Danube canal. Different hypotheses about the dynamics of genetic interchange have been postulated, ranging from a stable intergradation zone to complete mixing. We analysed the allozyme variation at nine loci in 14 or 17 populations, respectively, across the canal on two occasions: $2 \frac{1}{2}$ years and $4 \frac{1}{2}$ years after the opening. At the first sampling a strong genetic differentiation at three loci was found between the two invasion lines. This differentiation declined during the two-year period. The main effect was an assimilation of the Main populations according to the gene frequencies of the Danube populations, which suggest a swamping of the Main populations by Danube-type larvae. This inference is congruent with the overall water flow regime across the canal, i.e. active pumping from the Danube into the Main drainage system. The observed interchange processes allow some inferences to be made about the selective significance of the highly heterozygous allozyme loci in D. polymorpha.
\end{abstract}

Keywords: allozymes, biological invasions, European phylogroups, genetic non-equilibrium, heterosis, swamping, zebra mussel.

\section{Introduction}

Human activity can weaken or remove natural barriers for organismal communities, which were otherwise unbridgeable for some community members. The openings of newly constructed canals are well known examples that lead to faunal interchange, as for example the Lessepsian (Vermeij, 1991). Interchange may take place on different levels, at the species level or the genetic level. The outcome may be coexistence in newly organized assemblages, competitive exclusion of the inferior taxa, or genetic fusion by hybridization, if the taxa are still interfertile (Williamson, 1996). The last two situations can have dramatic effects in threatening the existence of rare taxa or genotypes (Rhymer \& Simberloff, 1996); however, little is known about the temporal dynamics of genetic mixing in metazoan animals. Here, we studied the genetic mixing of two differentiated zebra mussel populations.

The zebra mussel, Dreissena polymorpha, Pallas 1771, has extended its original distribution range from the Pontocaspian region to Western Europe since the beginning of the 19th century (Thienemann, 1950). It seems very likely that several canals built at that time or

*Correspondence.: E-mail: jakob@oekologie.biologie.uni-mainz.de before (Jazdzewski, 1980) have enabled the expansion, but there is also the possibility that $D$. polymorpha has survived the last glacial period as a relict in northern Central Europe (Thienemann, 1950). Two possible immigration routes for this 'classical' invader of Western Europe are evident: the northern route across the rivers and canals of the Dnieper, Prypet, Bug, Vistula and Midland canal to the river Rhine and further, and the southern route up the Danube (see Fig. 1). The first record of the zebra mussel appears in 1855 in the river Main - a tributary of the Rhine - and in 1868 in the upper Danube (Thienemann, 1950). At that time the two invasion groups could have come into contact through the first Main-Danube canal (opened in 1845), but this was probably restricted due to the small width of the canal and its low shipping traffic. This first canal was not maintained and was replaced by a large modern canal in 1992, which suddenly offered the potentiality of extensive contact and faunal exchange.

Our ability to date the secondary reunion of two invasion lines offers a good chance to investigate the temporal dynamics of a contact event. The two invasion lines probably originate from different long-existing populations of the original distribution area, namely those of the lower Dnieper and the Danube, and are 

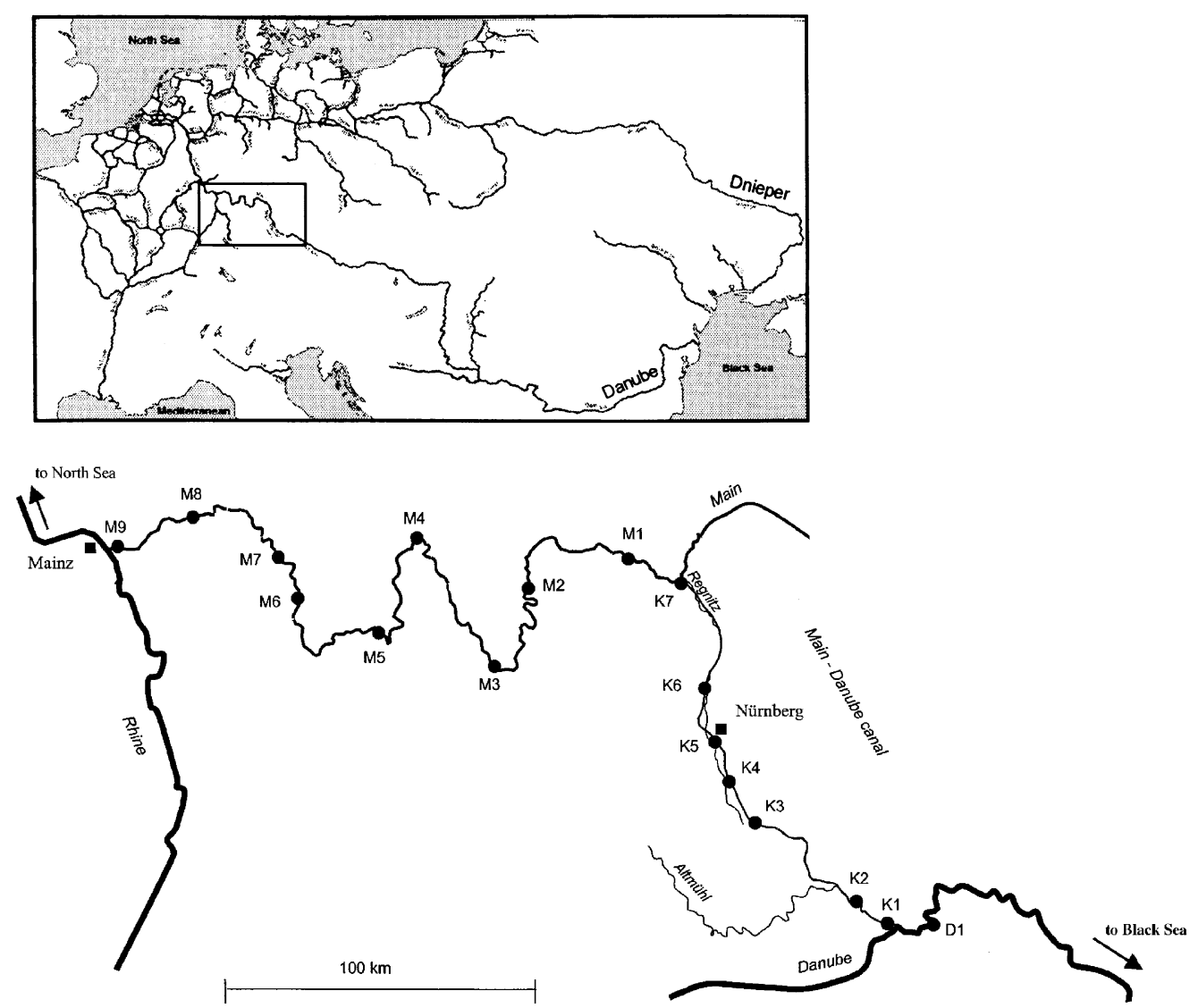

Fig. 1 Sampling locations in the Main (M1-M9), the canal (K1-K7) and the Danube (D1); the inset shows the study area in relation to the invasion routes.

therefore suspected to be genetically differentiated. The purpose of this study was to examine whether genetic exchange occurs and how the interchange proceeds during a time period of about 2 years. Three alternate hypotheses are proposed. $H_{1}$ : the once established contact zone stays geographically stable with restricted gene flow among the parapatric invasion populations. $\mathrm{H}_{2}$ : genetic interchange is asymmetric, with one invasion group displacing the other. $H_{3}$ : the two invasion populations intermingle slowly, which will appear as a widening of the intergradation zone.

The extraordinarily high heterozygosity found in newly invaded Dreissena polymorpha populations (Marsden et al., 1996) has given rise to investigations about possible heterosis effects in this species (Garton \& Haag, 1991). The rate and the pattern of an actual genetic interchange may allow us to make some inferences about the adaptive significance of the genetic variation.

\section{Materials and methods}

Dreissena polymorpha samples were collected across the watershed along the river Main, the Main-Danube canal and the Danube at about equal distances $(36 \mathrm{~km}$ on average) (see Fig. 1). At each location (about $2 \mathrm{~m}^{2}$ ) adult individuals of different sizes were randomly collected from the surface of stones taken near the riverbanks between 0.3 and $1 \mathrm{~m}$ depth. The 50 individuals from each location were frozen in liquid nitrogen until electrophoresis. Sampling was performed during two time periods, the first in October 1994 and July 1995 and the second in March and May 1997.

Whole mussel tissues from each specimen were homogenized in a grinding buffer. A short centrifugation step clarified the supernatant, which was used in a cellulose acetate electrophoresis according to Hebert \& Beaton. (1989). Twenty-four enzyme systems were screened for allozyme variability. From these the following eight polymorphic loci were found to be consistently interpretable and were scored for all populations in both time periods: 6-phosphogluconate dehydrogenase (6-PGD, E.C. 1.1.1.44), two loci of fumarase (FUM-I and FUM-II; the first migrates faster to the anode, E.C. 4.2.1.2), glyceraldehyde phosphate dehydrogenase (GAPD, E.C. 1.2.1.12), the more anodal locus of isocitrate dehydrogenase (IDH, E.C. 1.1.1.42), the less 
anodal locus of malate dehydrogenase $(M D H$, E.C. 1.1.1.37), glucosephosphate isomerase (GPI, E.C. 5.3.1.9) and glycyl-leucyl-peptidase (PEP, E.C. 3.4.11-13). The slower locus of $I D H$ appeared to be monomorphic across all samples and was excluded from further analysis. Alleles were designated in terms of mobility of their homomeric protein product relative to that of the most common allele across all populations at that locus.

Data handling and format conversion was done by the program G-STAT (Siegismund, 1997). The same program was used to calculate the spatial $\mathrm{F}_{\mathrm{ST}}$-values with their jackknife standard deviations according to Weir \& Cockerham (1984). Allele-specific $\mathrm{F}_{\mathrm{ST} \text {-values }}$ were provided by GDA (Lewis \& Zaykin, 1999). The temporal $\mathrm{F}_{\mathrm{ST}}$-values of each locus are the pairwise

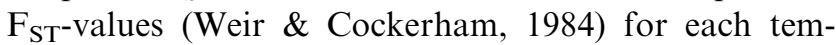
poral sample pair averaged across all locations, and were calculated with GENEPOP (Raymond \& Rousset, 1995). The genetic relationships among all populations was estimated by the restricted maximum likelihood method with the program CONTML from the package PHYLIP (1993). This method assumes that the lineages evolve independently by random processes, such as genetic drift (Felsenstein, 1981). Gene flow may be the antagonist of genetic differentiation in such a model. Rough confidence limits of the branch length (i.e. the expected accumulated variance) are provided by the program, to indicate the significance of the tree topology. Deviations from Hardy-Weinberg proportions were tested by exact tests with GENEPOP. Table-wide significance of tests was inferred from the sequential Bonferroni method (Rice, 1989).

\section{Results}

$F$-statistics reveal considerable spatial variation, i.e. $\mathrm{F}_{\mathrm{ST}^{-}}$ values greater than 1.96 times the standard deviation, for the three loci FUM-II, GAPD and GPI (Table 1). These loci also show the highest temporal $\mathrm{F}_{\mathrm{ST}}$-values (Table 1). A reduced allele frequency table therefore lists only the allele frequencies of these loci for both temporal samples (Table 2). There are only two alleles, which do not occur in all populations. In 1994/95 allele $F U M-I I^{*} 152$ was found in low frequencies in the Danube and canal populations, but not in any of the Main populations except for population M5. Conversely allele $F U M-I I^{*} 41$ was not present in the Danube and nearby canal populations $\mathrm{K} 1-\mathrm{K} 5$, but was present in the Main and the residual canal populations K6-K7. These alleles can thus be considered as nearly diagnostic for the Danube and Main populations, respectively, in the 1994/95-time period. In 1997 they lost their diagnostic pattern. The alleles at the loci GAPD and GPI showed persistently strong spatial frequency shifts along the geographical arrangement of the populations. The alleles $G A P D^{*} 74$ and $G P I^{*} 100$ for example were more abundant in the Danube than in the Main populations. The remaining loci were less variable and lacked regular geographical or temporal patterns.

Maximal values of observed heterozygosities for each time period appeared in the canal populations (K2, K4, K6 and K7) (Table 2). The 1994/95 samples showed in pairwise comparisons significantly lower heterozygosities than the 1997 samples: for observed heterozygosities $P=0.013$ and for expected heterozygosities $P=0.001$, using Wilcoxon's signed-ranks tests.
Table 1 Spatial $\mathrm{F}_{\mathrm{ST}}$-values $\pm \mathrm{SD}$ for 1994/95 and 1997 samples of Dreissena polymorpha, and mean temporal $\mathrm{F}_{\mathrm{ST}}$-values $\pm \mathrm{SD}$ between 1994/95 and 1997 samples; if more than two alleles at one locus are present, spatial $\mathrm{F}_{\mathrm{ST}}$-values for each allele are given; in two-allele loci overall and allelespecific $\mathrm{F}_{\mathrm{ST}}$-values are identical; significant values are indicated by an asterisk

\begin{tabular}{lcccc}
\hline Locus & Allele & $1994 / 95$ & 1997 & $\begin{array}{c}\text { Between 1994/95 } \\
\text { and } 1997\end{array}$ \\
\hline 6-PGD & & $0.014 \pm 0.010$ & $0.004 \pm 0.004$ & $0.004 \pm 0.028$ \\
FUM-I & & $0.012 \pm 0.008$ & $0.002 \pm 0.004$ & $0.001 \pm 0.012$ \\
FUM-II & & $0.035 \pm 0.014^{*}$ & $0.009 \pm 0.005$ & $0.043 \pm 0.038$ \\
& 152 & 0.065 & 0.018 & \\
& 100 & 0.020 & 0.002 & \\
GAPD & 41 & 0.026 & 0.015 & \\
$I D H$ & & $0.193 \pm 0.032^{*}$ & $0.088 \pm 0.026^{*}$ & $0.013 \pm 0.028$ \\
$M D H$ & & $0.009 \pm 0.010$ & $0.004 \pm 0.004$ & $0.004 \pm 0.019$ \\
$G P I$ & $0.001 \pm 0.005$ & $0.001 \pm 0.004$ & $0.001 \pm 0.013$ \\
& & $0.032 \pm 0.011^{*}$ & $0.014 \pm 0.005^{*}$ & $0.015 \pm 0.032$ \\
& 113 & 0.010 & 0.006 & \\
PEP & 100 & 0.038 & 0.016 & \\
& 88 & 0.040 & 0.021 & \\
& 107 & $0.008 \pm 0.004$ & $0.012 \pm 0.009$ & $0.013 \pm 0.025$ \\
& 100 & 0.007 & 0.017 & \\
\hline
\end{tabular}


Table 2 Allelic frequencies of the three most variable loci of Dreissena polymorpha and mean heterozygosities across all polymorphic loci

\begin{tabular}{|c|c|c|c|c|c|c|c|c|c|c|c|c|c|c|c|c|}
\hline \multirow{2}{*}{\multicolumn{2}{|c|}{ Samples }} & \multicolumn{4}{|c|}{$F U M-I I$} & \multicolumn{3}{|c|}{$G A P D$} & \multicolumn{4}{|c|}{$G P I$} & \multicolumn{2}{|c|}{ Het observed } & \multicolumn{2}{|c|}{ Het expected } \\
\hline & & 152 & 100 & 41 & $N$ & 100 & 74 & $N$ & 113 & 100 & 88 & $N$ & Mean & SD & Mean & SD \\
\hline \multirow[t]{2}{*}{ D1 } & $1994 / 95$ & 0.05 & 0.95 & & 42 & 0.39 & 0.61 & 48 & 0.14 & 0.68 & 0.18 & 50 & 0.39 & 0.15 & 0.42 & 0.15 \\
\hline & 1997 & 0.10 & 0.84 & 0.06 & 26 & 0.46 & 0.54 & 2 & 0.19 & 0.61 & 0.20 & 26 & 0.39 & 0.15 & 0.44 & 0.09 \\
\hline \multirow[t]{2}{*}{ K1 } & $1994 / 95$ & 0.07 & 0.93 & . & 22 & 0.33 & 0.67 & 49 & 0.16 & 0.66 & 0.19 & 51 & 0.38 & 0.15 & 0.41 & 0.12 \\
\hline & 1997 & 0.05 & 0.91 & 0.04 & 50 & 0.38 & 0.62 & 50 & 0.20 & 0.66 & 0.1 & 50 & 0.44 & 0.16 & 0.45 & 0.12 \\
\hline \multirow{2}{*}{$\mathrm{K} 2$} & 1994/S & 0.14 & 0.86 & - & 33 & 0.40 & 0.60 & 48 & 0.17 & 0.56 & 0.2 & 47 & 0.45 & 0.15 & 0.45 & 0.10 \\
\hline & 19 & 0.03 & 0.86 & 0.11 & 50 & 34 & 0.66 & 5 & 1 & 0.65 & 0 & $J$ & 14 & .16 & 0.44 & 0.08 \\
\hline \multirow[t]{2}{*}{ K3 } & $1994 / 95$ & 0.16 & 0.84 & - & 47 & 0.30 & 0.7 & 5 & 0.12 & 0.75 & 0 . & 5 & 0.44 & 0.11 & 0.42 & 0.07 \\
\hline & 199 & 0.01 & 0.91 & 0.08 & 50 & 0.41 & 0.59 & 50 & 0.19 & 0.55 & 0.2 & $J$ & 0.43 & 0.14 & 0.45 & 0.13 \\
\hline \multirow[t]{2}{*}{ K4 } & $1994 / 9$ & 0.09 & 0.91 & - & 45 & 0.44 & 0.56 & 48 & 0.14 & 0.63 & 0.2 & 5 & 0.42 & 0.14 & 0.44 & 0.12 \\
\hline & 1997 & 0.02 & 0.85 & 0.13 & 50 & 0.49 & 0.51 & 5 & & 0.66 & 0. & 5 & & 0.15 & .46 & 0.10 \\
\hline \multirow[t]{2}{*}{ K5 } & 19 & 0 & 0. & - & 38 & 2 & 0. & 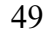 & 7 & 0.50 & 0 & & & 0.16 & 0 & 0.17 \\
\hline & 19 & 0.11 & 0.84 & 0.05 & 5 & 0.61 & 0.3 & 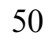 & 0.14 & 0.66 & 0 & & 0 & 0.09 & 0.44 & 0.08 \\
\hline \multirow[t]{2}{*}{ K6 } & 1994/s & 0.01 & 0.98 & 0.0 & 46 & 0.73 & 0.2 & 4 & 0.28 & 0.48 & 0.2 & $J$ & 0.46 & 0.19 & 0.44 & 0.18 \\
\hline & 1997 & 0.07 & 0.84 & 0.09 & 50 & 0.62 & 0.38 & 5 & 0.24 & 0.56 & 0.2 & 5 & 0.45 & 0.10 & .49 & 0.10 \\
\hline \multirow[t]{2}{*}{ K7 } & $1994 / 95$ & 0.02 & 0.96 & 0.02 & 43 & 0.80 & 0.20 & 50 & 0.17 & 0.42 & 0. & 50 & 0.42 & 0.15 & .41 & 0.16 \\
\hline & 19 & 0.0 & 0. & 0. & 50 & & 0.2 & 5 & & 0.51 & 0 & & & 0.23 & 15 & 0.16 \\
\hline \multirow[t]{2}{*}{ M1 } & $1994 / 95$ & - & 0.93 & 0.0 & 48 & 0.78 & 0.2 & . & 0. & 0.45 & 0 . & & 0 . & 0.12 & 0.42 & 0.15 \\
\hline & 199 & 0.04 & 0.89 & 0.07 & 50 & 0.61 & 0.3 & 5 & 0.23 & 0.49 & 0.2 & $J$ & 0. & 0.14 & 0.45 & 0.12 \\
\hline \multirow[t]{2}{*}{ M2 } & $1994 / 9$ & - & 0.99 & 0.01 & 47 & 0.82 & 0.18 & 45 & 0.12 & 0.48 & 0.4 & 50 & 0.39 & 0.18 & 0.42 & 0.18 \\
\hline & 1997 & 0.01 & 0.84 & 0.15 & 50 & 0.67 & 0.33 & 50 & 0.23 & 0.51 & 0.2 & 50 & 5 & 0.16 & 48 & 0.10 \\
\hline \multirow[t]{2}{*}{ M3 } & $1994 / 95$ & 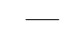 & 0.9 & 0.0 & 49 & & 0.1 & 4 & & 0.45 & 0 & 4 & & 8 & & 0.15 \\
\hline & 19 & 0.02 & 0.8 & 0.1 & 5 & 0.79 & 0.2 & 5 & 0.33 & 0.53 & 0 . & 5 & 0 & 0.14 & 0.45 & 0.09 \\
\hline \multirow[t]{2}{*}{ M4 } & $1994 / 95$ & - & 0.91 & 0.09 & 4. & 0.80 & 0.2 & 4 & 0.16 & 0.47 & 0.3 & 47 & 0.42 & 0.14 & 0.43 & 0.14 \\
\hline & 1997 & - & 0.86 & 0.14 & 50 & 0.73 & 0.27 & 50 & 0.26 & 0.53 & 0.21 & 50 & 0.43 & 0.16 & 0.46 & 0.11 \\
\hline \multirow[t]{2}{*}{ M5 } & $1994 / 95$ & 0.02 & 0.95 & 0.03 & 50 & 0.84 & 0.16 & 45 & 0.20 & 0.41 & 0.39 & 49 & 0.33 & 0.14 & 0.38 & 0.16 \\
\hline & 195 & 0.02 & 0.8 & 0.1 & 50 & & 0.2 & 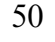 & & 0.50 & 0. & 5 & & 0.21 & 4 & 0.12 \\
\hline \multirow[t]{2}{*}{ M6 } & $1994 / 95$ & - & 0.9 & 0.0 & 40 & & 0.2 & 3 & & 0.46 & 0. & 5 & 0.42 & 0.18 & 0.44 & 0.16 \\
\hline & & - & & 0. & 50 & & 0. & 5 & & 0.54 & 0 & 5 & 0.44 & 0.12 & 0.46 & 0.10 \\
\hline M7 & 1997 & 0.06 & 0.89 & 0.05 & 50 & 0.75 & 0.25 & 50 & 0.22 & 0.44 & 0.34 & 50 & 0.40 & 0.13 & 0.44 & 0.14 \\
\hline M8 & 1997 & 0.03 & 0.88 & 0.09 & 50 & 0.76 & 0.24 & 50 & 0.25 & 0.44 & 0.31 & 50 & 0.40 & 0.17 & 0.44 & 0.13 \\
\hline M9 & 1997 & 0.01 & 0.93 & 0.06 & 50 & 0.76 & 0.24 & 50 & 0.17 & 0.42 & 0.41 & 50 & 0.38 & 0.13 & 0.43 & 0.15 \\
\hline
\end{tabular}

Out of the 222 exact tests for Hardy-Weinberg equilibrium performed on the 1994/95 and 1997 samples for each locus and population, 28 were significant at a significance level of 0.05 . However they appeared to be randomly scattered and did not render prominent any population or locus. A table-wide Bonferroni correction left only one test as weakly significant (population K7/1997 at locus PEP, $P=0.0002$ ). Given this almost overall Hardy-Weinberg equilibrium, allele frequencies were used to construct the unrooted maximum likelihood trees of genetic relationships among populations (Fig. 2). The 1994/95 samples show a distinct bipartition into a Danube/Southern canal group (populations D1, $\mathrm{K} 1-\mathrm{K} 4$ ) and a Main/Northern canal group (populations K5-K7, M1-M6). There are two additional significant internal branches, which places the population K4 intermediate and sets off the populations M1 and M4 against the rest of the Main group. There is also a tendency for the northern canal populations to be more intermediate than the Main populations. This strong geographical pattern is not reflected in the 1997 samples. There is no longer a clear cut bipartition. The significant internal branches indicate only a weak geographical separation into the Danube/Canal populations and the Main populations with M1 and K7 interchanged.

The three most informative loci (FUM-II, GAPD and $G P I)$ concerning spatial and temporal variation among samples have been chosen to construct Fig. 3. From each locus the most variable alleles, i.e. FUM-II*152, $G A P D^{*} 74$ (in this two-allele system both alleles are equally variable), and $G P I^{*} 88$, were standardized to obtain a comparable range of their frequencies between 0 and 1 . The mean and variance of these standardized frequencies were calculated after checking for the same spatial polarities, i.e. the complement frequency of $G P I^{*} 88$ was used with the other frequencies unchanged. 
In 1994/95 a profound genetic cline appeared between K4 and K5, in 1997 however, the steepest cline was between $\mathrm{K} 6$ and $\mathrm{K} 7$. Between the two time periods there was a general cline degradation and widening, with the canal populations $\mathrm{K} 2-\mathrm{K} 4$ becoming more Main-like and the canal and Main populations K5-M6 becoming more Danube-like. The populations D1 and K1 exhibited least change, whereas K3, K5 and M3 showed the greatest change.

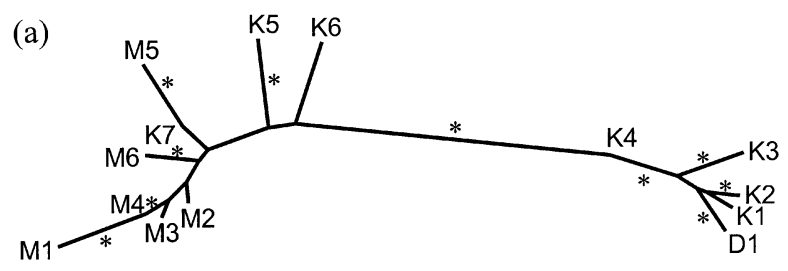

(b)

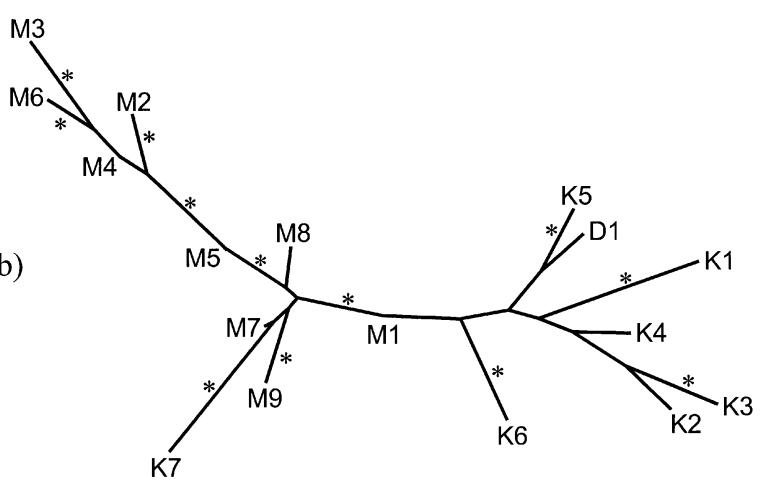

Fig. 2 Restricted maximum likelihood tree of genetic relationships among all populations of Dreissena polymorpha sampled in 1994/95 (a) and 1997 (b); asterisks indicate branches significant different from zero; for population abbreviations see Fig. 1 .

\section{Discussion}

Several studies using allozyme electrophoresis indicate that Dreissena polymorpha has extraordinarily high levels of genetic variability, ranking among the highest reported heterozygosity values among animals (Boileau \& Hebert, 1993; Marsden et al., 1996; Zielinski et al., 1996). For North American populations, observed (individual) heterozygosities are reported in the range from $29 \%$ to $43 \%$ (Marsden et al., 1996) and for European populations in the range from $27 \%$ to $46 \%$ (Boileau \& Hebert, 1993; Marsden et al., 1995). Our population values of observed heterozygosities, including the monomorphic locus $I D H$, range from $29 \%$ to $44 \%$, thus falling within the range. No geographical differences are obvious, despite the different colonization history. North America was invaded in the late 1980s, whereas our study area was invaded about 150 years ago. Genetic bottlenecks during invasion of D. polymorpha seem to occur less frequently, which may be a general characteristic of molluscs with planktonic larvae. In addition to the high larval dispersal ability, adult dreissenids have the capacity of rapid and longdistance dispersal by clinging to the hulls of ships with their byssal threads (Johnson \& Carlton, 1996). These combined dispersal characteristics may have helped the colonization of new areas by large numbers of individuals or by multiple colonization events without much loss of genetic diversity. An alternate hypothesis to explain the maintenance of high levels of heterozygotes is indicated by fitness differences among genotypes. A heterosis effect is reported for benthic life history stages of molluscs, including survival in post-larval oysters (Zouros et al., 1983) and growth rate in adult
Fig. 3 Mean and variance of standardized, most informative allele frequencies of Dreissena polymorpha across the transect populations (for abbreviations see Fig. 1).

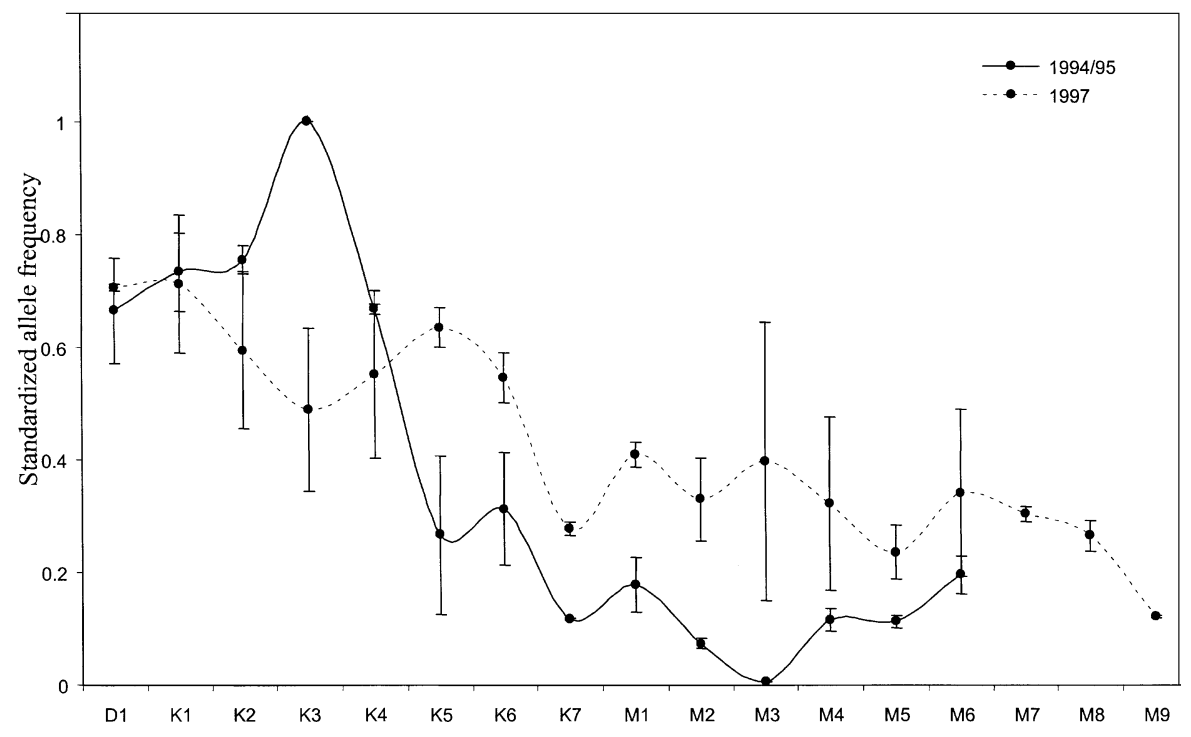

(C) The Genetics Society of Great Britain, Heredity, 86, 103-109. 
D. polymorpha (Garton \& Haag, 1991; see however, Boileau \& Hebert, 1993).

We have found two genetically distinct groups for the Danube and Main populations, visible still two and a half years after the canal opening. The genetic differentiation is mainly based on the loci $F U M-I I$ with the nearly diagnostic alleles 152 and $41, G A P D$ and $G P I$. With the high dispersal abilities, it is likely that this differentiation reflects an old differentiation between the lower Dnieper and Danube, from where the two invasion lines probably emerged. These two invasion lines seem to represent two major European clusters found by Marsden et al. (1995): their single Danube (Budapest) population against the rest (Northern Europe from The Netherlands to an unidentified Volga reservoir). Our alleles can roughly be related to their alleles by relative mobilities, considering different electrophoresis conditions. So for example, the two major groups differ correspondingly by their dominant alleles at the locus $G A P D$. The intra-European differentiation ranks among the highest transcontinental European-North American differentiations (see Marsden et al., 1995).

Our data show that the new opportunity for close contact of the two major European phylogroups after the construction of the Main-Danube canal has led to a genetic interchange. Genetic mixing of individuals is evidenced by overall Hardy-Weinberg proportions, the increase in heterozygosity, and the occurrence of one hybrid genotype FUM-II*41/152 in the 1997 sample of K7. The expectation of this hybrid genotype for 1997 is either calculated as low ( 4 individuals). The intergradation zone appears to be geographically dynamic and expanding, thus rejecting $H_{1}$ (see introduction) and supporting $H_{3}$. Although the interchange is highly asymmetric, a displacement without mixing $\left(\mathrm{H}_{2}\right)$ is not indicated. The asymmetry can be attributed to the artificial water flow system maintained in the canal. The upper reservoirs of the 16 locks located around the watershed between $\mathrm{K} 3$ and $\mathrm{K} 4$ are mainly fed by water coming from a reservoir, in which $\mathrm{K} 2$ has been sampled. Large amounts of this water $\left(\sim 125\right.$ million $\mathrm{m}^{3}$ per year $)$ are transferred across the canal to the Main basin in the course of a water management strategy. The sample sites of $\mathrm{D} 1$ and $\mathrm{K} 1$ are relatively decoupled from this main water flow cycle and are thus genetically less influenced. In 1994/95 the genetic cline was strongest near the watershed (between K3 and K5), implying that initial colonization (1992-94) was influenced by local nearby populations of the tributaries and by shipping traffic. Invasion of the canal happened quite rapidly. High densities up to 10000 individuals per $\mathrm{m}^{2}$ were first recorded in 1993 (German Federal Institute of Hydrology, personal communication). In 1997 the major cline shifted northwards (between K6 and K7) and the northern populations were affected the most. As the shipping traffic is equal in both directions across the apex of this canal system, these results stress the importance of larval movements in moving water bodies. Upstreamlocated populations (i.e. K2 to K4 near the watershed) can change the genetic composition of downstream populations by larval swamping, but not vice versa. The larval influence on the established Main populations seems to reach as far as sample site M8 about $450 \mathrm{~km}$ away. One generation per year is expected for Rhine populations (Neumann et al., 1993). Therefore two larval cohorts may have contributed to the genetic swamping during the study period. This is not surprising, as D. polymorpha larvae are estimated to travel more than $300 \mathrm{~km}$ downstream before settlement (Stoeckel et al., 1997). Such a strong unidirectional gene flow pattern may be typical of riverine populations of dreissenids. In newly colonized lacustrine environments the situation is probably different. Initially formed genetically diverse pocket populations may be stable for many generations due to low and random average larval dispersal distances (Ibrahim et al., 1996; Wilson et al., 1999).

The observed dynamics of genetic interchange allow some implications about the selective significance of the allozyme loci involved. The genetic differentiation between the Main and Danube lines may have been built up by chance alone or by different selection regimes in the different environments. With neutral behaviour of the alleles the interchange would end up by complete mixing and matching of the two lines $\left(H_{3}\right)$. Environmentally adapted alleles would maintain their frequency in their respective environments. The environment can be either external (intergradation zone does not move; $H_{1}$ ) or refer to the internal genetic background (intergradation zone can move; $\mathrm{H}_{2}$ ) (Barton \& Gale, 1993). The rapid genetic change and apparent genetic hybridization of the long established Main populations supports the third hypothesis $\left(H_{3}\right)$ of neutral alleles. However, the strong influence of larval swamping in riverine environments could even displace slightly advantageous alleles. A major consequence of canal construction could thus be the downstream swamping of maladapted genes. This pattern of balance will be investigated by further temporal sampling on a larger geographical scale.

\section{Acknowledgements}

We thank two anonymous reviewers and the editor John Brookfield, who made valuable comments. This study was funded by the German Federal Institute of Hydrology (BfG), Koblenz and the Centre for Environmental Studies (ZfU) at the University, Mainz. 


\section{References}

BARTON, N. H. AND GALE, K. S. 1993. Genetic analysis of hybrid zones. In: Harrison, R. G. (ed.) Hybrid Zones and the Evolutionary Process, pp. 13-45. Oxford University Press, New York.

BOILEAU, M. G. AND HEBERT, P. D. N. 1993. Genetics of the zebra mussel (Dreissena polymorpha) in populations from the Great Lakes region and Europe. In: Nalepa, T. F. and Schloesser, D. W. (eds) Zebra Mussels: Biology, Impacts, and Control., pp. 227-238. Lewis Publishers, Boca Raton.

FELSENSTEIN, J. 1981. Evolutionary trees from gene frequencies and quantitative characters: finding maximum likelihood estimates. Evolution, 35, 1229-1242.

GARTON, D. W. AND HAAG, w. R. 1991. Heterozygosity, shell length, and metabolism in the European mussel, Dreissena polymorpha, from a recently established population in Lake Erie. Comp. Biochem. Physiol., 99A, 45-48.

HEBERT, P. D. N. AND BEATON, M. J. 1989. Methodologies for Allozyme Analysis Using Cellulose Acetate Electrophoresis: a Practical Handbook. Helena Laboratories, Beaumont, TX.

IBRAHIM, K. M., NICHOLS, R. A. AND HEWITT, G. M. 1996. Spatial patterns of genetic variation generated by different forms of dispersal during range expansion. Heredity, 77, 282-291.

JAZDZEWSKI, K. 1980. Range extension of some Gammaridean species in European inland waters caused by human activity. Crustaceana, 6, 84-102.

JOHNSON, L. E. AND CARLton, J. T. 1996. Post establishment spread in large-scale invasions: dispersal mechanisms of the zebra mussel Dreissena polymorpha. Ecology, 77, 1684-1690.

LEWIS, P. O. AND ZAYKIN, D. 1999. GDA - a computer program for genetic data analysis. Statistical Genetics Summer Institute, North Carolina State University, Raleigh, NC.

MARSDEN J. E., SPIDLE, A. MAY, B. 1995. Genetic similarity among zebra mussel populations within North America and Europe. Can. J. Fish. Aquat. Sci., 52, 836-847.

MARSDEN, J. E., SPIDLE, A. P. AND MAY, B. 1996. Review of genetic studies of Dreissena spp. Amer. Zool., 36, 259-270.

NEUMANN, D., BORCHERDING, J. AND JANTZ, J. 1993. Growth and seasonal reproduction of Dreissena polymorpha in the Rhine river and adjacent waters. In: Nalepa, T. F. and Schloesser, D. W. (eds) Zebra Mussels: Biology, Impacts, and Control., pp. 95-109. Lewis Publishers, Boca Raton.
PHYLIP. 1993. Phylogeny inference package, version 3.5c. Felsenstein, J., Department of Genetics, University of Washington, Seattle, WA.

RAYMOND, M. AND ROUSSET, F. 1995. GENEPOP (version 1.2): population genetics software for exact tests and ecumenicism. J. Hered., 86, 248-249.

RHYMER, J. M. AND SIMBERLOFF, D. 1996. Extinction by hybridization and introgression. Ann. Rev. Ecol. Syst., 27, 83-109.

RICE, W. R. 1989. Analyzing tables of statistical tests. Evolution, 43, 223-225.

SIEGISMUND, H. R. 1997. G-STAT, version 3.2. Genetical statistical programs for the analysis of population data. Department of Plant Ecology, University of Copenhagen, Oster Farimagsgade 2D, 1353 Copenhagen K, Denmark.

STOECKEL, J. A., SCHNEIDER, D. W., SOEKEN, L. A., BLODGETT, K. D. ET AL. 1997. Larval dynamics of a riverine metapopulation: implications for zebra mussel recruitment, dispersal, and control in a large river system. J. North Am. Benthol. Soc., 16, 586-601.

THIENEMANN, A. 1950. Verbreitungsgeschichte der Süßwassertierwelt Europas. In: Thienemann, A. (ed.) Die Binnengewässer, vol. XVIII. Schweizerbart'sche Verlag, Stuttgart.

VERMEIJ, G. J. 1991. When biotas meet: understanding biotic interchange. Science, 253, 1099-1104.

WEIR, B. S. AND COCKERHAM, C. C. 1984. Estimating $F$-statistics for the analysis of population structure. Evolution, 38, 1358-1370.

Williamson, M. 1996. Biological Invasions. Chapman \& Hall, London.

WILSON, A. B., NAISH, K.-A. AND BOULDING, E. G. 1999. Multiple dispersal strategies of the invasive quagga mussel (Dreissena bugensis) as revealed by microsatellite analysis. Can. J. Fish. Aquat. Sci., 56, 2248-2261.

ZIELINSKI, R., SOROKA, M. AND WACHOWIAK-ZIELINSKA, M. 1996. Genetic variability in selected Polish population of Dreissena polymorpha (Pallas) (Bivalvia: Dreissenidae). J. Appl. Genet., 37, 105-120.

ZOUROS, E., SINGH, S. M., FOLTZ, D. W. AND MALlET, A. L. 1983. Post-settlement viability in the American Oyster (Crassostrea virginica): an overdominant phenotype. Genet. Res., 41, 259-270. 